\title{
Wind Catcher and Trans-evaporative Cooling Residential Integration in Arid Region
}

\author{
Isam Janajreh*, Kamel Adouane, Mohammed Hussain \\ Masdar Institute of Science and Technology, Abu Dhabi, UAE
}

\begin{abstract}
The wind catcher potential for providing occupants comfort conditions is been investigated under trans-evaporative cooling for two-level simple dwelling in arid region. The wind catcher runs on the reverse chimney concept in which the upper wind is captured (by means of passive or active louvers) and is impregnated with moisture that consequently reducing its temperature and increasing its density. This results in a cold downdraft stream in the tower which is used to the conditioning of the dwelling space. This work uses a high fidelity computational fluid dynamics (CFD) of multiple species and two-phase flow to examine the performance of the wind catcher subjected to water injection in the form of mist of 10 micron droplet size. The air flow is governed by the none-isothermal Navies-stokes equations which are coupled with energy equation in a conjugated heat transfer in accounting to the inner building walls and the convective conditions for the rest of the building. The water droplet is governed by the discrete phase that also in direct coupling with the continuous phase representing the wind. Flow parameters including velocity, temperature, relative humidity and droplets dispersion are evaluated and their distribution is presented. The setup is tested at different regional conditions manifested in the incoming wind speed, present relative humidity level and temperature sensitivity. Results show that in the average UAE summer conditions $\left(42^{\circ} \mathrm{C}\right.$ and $50 \%$ R. humidity) the role of wind catcher in evaporative cooling was deemed unimportant. However under pre-dehumidification near $25 \% \mathrm{R}$. humidity a significant temperature drop of $10{ }^{\circ} \mathrm{C}$ and reasonable R. humidity of near $60 \%$ can be obtained when integrating wind catcher to isolated dwellings.
\end{abstract}

Keywords: Wind catcher, cool tower, trans-evaporative cooling

\section{Introduction}

Wind catchers, Badings or Baud-Geer, found in Middle East are historical signature of the importance of cooling for the comfort of human being. In the age of greenhouse gas emission mitigation, fossil fuel energy offsetting, and renewable energy several evaporative cooling solutions are observing innovative renascence. A good review of these structures are given in the work of Roberts [1] covering the simple form that provides sensible heat and natural downdraft to the trans-evaporative form. The new concepts enable better arrangement of the introduced moisture in the form of mist to ease its evaporation and

\footnotetext{
${ }^{*}$ Corresponding author. Tel.: +97128109130

Fax: +97128109999; E-mail: ijanajrehijanajreh@masdar.ac.ae

(C) 2017 International Association for Sharing Knowledge and Sustainability

DOI: $10.5383 /$ ijtee.14.01.001
}

temperature reduction that equivalent to the latent heat of evaporation.

Amongst the pioneers who analyzed and design cooling towers is Bahodori [2]. He used aggressive wind values that exaggerate the application in middle-east. Other forerunners who investigate the air flow rate and temperature are Kent and Thompson [3]. They stipulated their design in the arid western US states (Arizona and Nevada) as well as Saudi Arabia. Badran [4] under a strict assumption of the flow have evaluated analytically the role of height that the wind catcher plays for the different regions in Jordan. The previous work however fails to account to the change in density and temperature nor does it provide their distribution. This information is the essential components in assessing the performance of the 
wind catcher. Ghadiri et al. [5] worked on CFD modelling of a four sided wind catcher. Their work was focused on determining the applicability of CFD in analyzing wind catchers. They studied the model under various turbulence models and varied the angle of the incoming wind. They found that the CFD models gave highly accurate results for perpendicularly entering wind but were not so accurate for wind entering at other angles. $\mathrm{Su}$ et al. [6] worked on CFD based flow rate validation of Monodraught ${ }^{\mathrm{TM}}$ wind catcher, which is a commercially available wind catching setup. They did both experimental and CFD modelling for this device and found that CFD analysis was much in agreement with the experimental flow rates recorded. Montazeri et al. [7] worked on a wind tower of a similar design as a Monodraught ${ }^{\mathrm{TM}}$ in Iran. They did experimental testing, analytical modelling and CFD analysis. They found that $20 \%$ higher efficiency could be achieved when the wind catcher inlet is placed at $90^{\circ}$ incident angle to the air flow direction. This work is inline of the above sited work but with more focus on simple dwellings and shows the velocity, relative humidity, and temperature distributions under different wind, temperature, and relative humidity inlet conditions to the wind catcher.

\section{Methodology and Problem Setup}

The two dimensional baseline cutaway of the geometry with dimensions and boundary conditions is depicted in Fig. 1 (similar geometry of Badran's [4]). It sets on $10.95 \mathrm{mx} 11.75 \mathrm{~m}$ including the cool tower. The two floors are in direct access to the downdraft of the tower through two openings as seen in the Fig. 1. They are all thermally coupled through the flowing fluid and through the conductive structural walls of the tower and ceiling of the $1^{\text {st }}$ floor. The geometry is also subjected to the equivalent walls conductivity and convective surrounding environment.

The baseline geometry is subject to incoming wind which is first is captured and directed into the tower through louvers or vanes which tunnel the flow downwards. Following the tower entry and as the flow streamlined downwards, an injection line of water moisture is encountered at top to impregnate the incoming fluid with the stipulated moisture amount. The tower length provide enough residence time for the water droplet to evaporate. The water injector line is directed downwards at low velocity of $10 \mathrm{~m} / \mathrm{s}, 10$ micros droplet size, and a total baseline mass of nearly $0.01 \mathrm{~kg} / \mathrm{s}$ that insures near an acceptable relative humidity level downstream in the conditioned space. The fluid exit from the domain via the two window openings for each conditioned floor. The ground is considered thermally insulated concrete different from the surrounding convective walls, kinetically however is subjected to noslip and no-penetration velocity wall that similar to all the surrounding walls.

\subsection{Governing Equations}

Two formulations are used to solve the two-phase flow; the Eulerian that governs the continuous gaseous phase and it consists of two species (air and water vapor) and the Lagrangian that track the dispersed or discrete water droplets phase and solve for their trajectories. The flow field is considered as a steady, two dimensional, turbulent and non-isothermal of two species. The conjugate heat transfer model is also seen in some previous works related to evaporation [8].

Continuous field equations: The continuous phase is governed by the Navier-Stokes equations that represented by the continuity (Eq.1), momentum (Eq. 2) and energy (Eq. 3) and these are written as:

$$
\frac{\partial\left(\rho u_{i}\right)}{\partial x_{i}}=S_{m}
$$

where $\rho$ is the gas density $\left(\mathrm{kg} / \mathrm{m}^{3}\right), u_{i}$ is the velocity vector

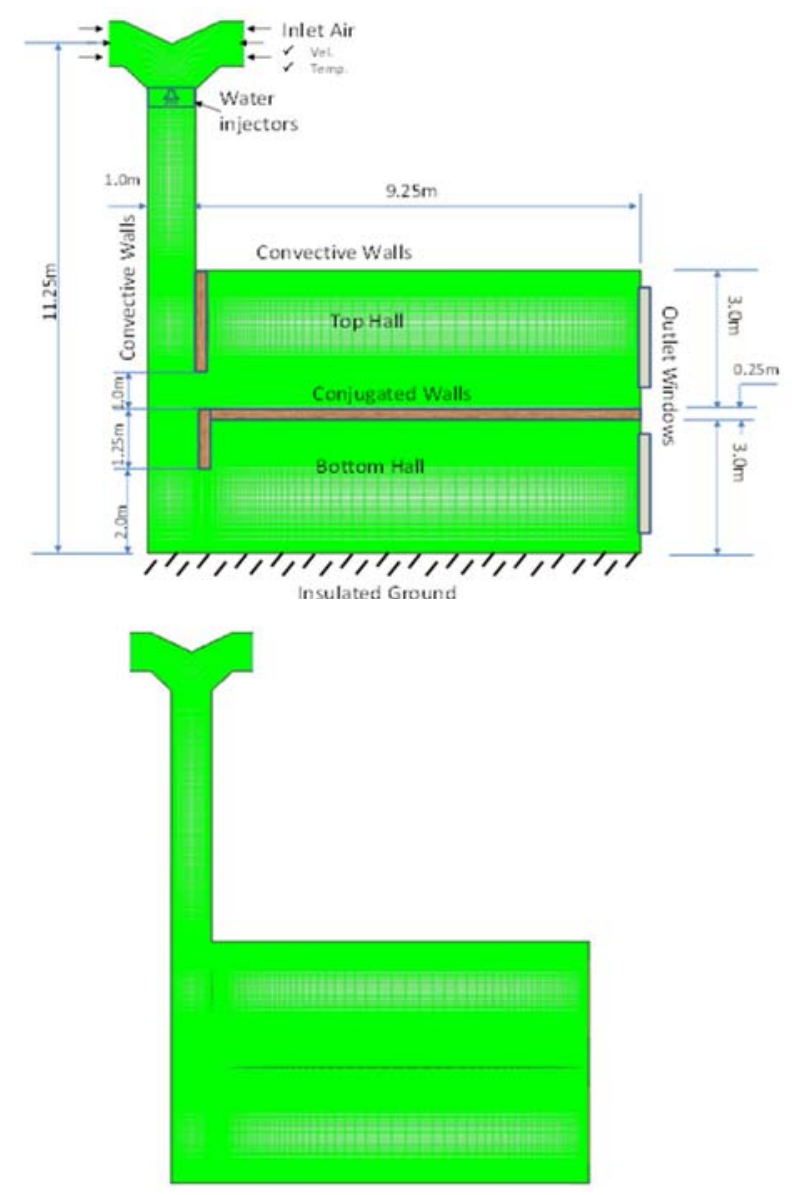

Fig. 1: Baseline geometry and computational domain (Top) Height-1 and (Bottom) Height-2

$(\mathrm{m} / \mathrm{s})$ and $S_{m}$ is the mass source term $\left(\mathrm{kg} / \mathrm{s} \cdot \mathrm{m}^{3}\right)$ which is added or removed from the continuous phase due to evaporation or condensation of the water droplets. The momentum equation is written as:

$$
\begin{gathered}
\frac{\partial}{\partial x_{i}}\left(\rho u_{i} u_{j}\right)=\frac{\partial p}{\partial x_{j}}+\frac{\partial}{\partial x_{j}}\left[\mu\left(\frac{\partial u_{i}}{\partial x_{j}}+\frac{\partial u_{j}}{\partial x_{i}}\right)\right]+ \\
\frac{\partial}{\partial x_{j}}\left(-\rho \overline{u_{\imath}^{\prime} u_{j}^{\prime}}\right)+f_{i}
\end{gathered}
$$


Boussinesq hypothesis has been employed to relate the Reynolds stresses $\left(\rho \overline{u_{\imath}^{\prime} u_{\jmath}^{\prime}}\right)$ to the mean velocity gradient, $p$ is the static pressure $(\mathrm{Pa}), \mu$ is the dynamic viscosity $(\mathrm{Pa} \cdot \mathrm{s})$ and $f_{i}$ is the external body force in $\mathrm{j}^{\text {th }}$ direction $\left(\mathrm{N} / \mathrm{m}^{3}\right)$. The energy equation is also described as:

$$
\frac{\partial}{\partial x_{j}} u_{i}(\rho E+p)=\frac{\partial}{\partial x_{j}}\left[\left(\gamma+\frac{C_{p a} \mu_{t}}{P r_{t}}\right) \frac{\partial T}{\partial x_{j}}-\sum_{j} h_{j} J_{j}\right]+S_{h}(3)
$$

where $\gamma$ is the thermal conductivity of the fluid $(\mathrm{W} / \mathrm{m} \cdot \mathrm{K})$, $c_{p a}$ is the specific heat of air at constant pressure $(\mathrm{J} / \mathrm{kg} \cdot \mathrm{K})$, $\mu_{t}$ is the turbulent viscosity $(\mathrm{Pa} \cdot \mathrm{s}), \operatorname{Pr}_{t}$ is the turbulent Prandtl number, $T$ is the temperature $(\mathrm{K}), h_{j}$ is the enthalpy of the species $(\mathrm{J} / \mathrm{kg}), J_{j}$ is the diffusion flux of species $\mathrm{j}\left(\mathrm{kg} / \mathrm{m}^{2} \cdot \mathrm{s}\right)$ and $S_{h}$ is any volumetric source. The term $E$ is defined as follows

$$
E=\sum h_{j} Y_{j}+\frac{u^{2}}{2}
$$

where $Y$ is the species mass fraction and $\mathrm{h}$ is the specific enthalpy. Species transport equation of water vapor mass fraction $\left(\mathrm{Y}_{\mathrm{H}_{2} \mathrm{O}}\right)$ into air is also used to govern the two participating/mixture species and written as:

$\frac{\partial}{\partial x_{j}}\left(\rho Y_{H_{2} o} u_{i}\right)=\frac{\partial}{\partial x_{j}}\left[\left(\rho D_{H_{2} o}+\frac{\mu_{t}}{S c_{t}}\right) \frac{\partial Y_{2} o}{\partial x_{j}}\right]+S_{H_{2} o}$

where $D_{H 2 O}$ is the diffusion coefficient of water vapor into air $\left(2.88 \times 10^{-5}\right), S_{c t}$ is the turbulent Schmidt number $(0.7)$ and $S_{H 2 O}$ is the water vapor added to or removed from the air due to evaporation or condensation. Additional to these scalar equations, the two turbulent scalars which model its eddy viscosity in the form of turbulent kinetic energy and its dissipation are written as:

$$
\begin{gathered}
\frac{\partial}{\partial x_{i}}\left(\rho k u_{i}\right)=\frac{\partial}{\partial x_{j}}\left[\left(\mu+\frac{\mu_{t}}{\sigma_{k}}\right) \frac{\partial k}{\partial x_{j}}\right]+G_{k}+G_{b}-\rho \varepsilon-Y_{M}+ \\
S_{k} \\
\frac{\partial}{\partial x_{i}}\left(\rho \varepsilon u_{i}\right)=\frac{\partial}{\partial x_{j}}\left[\left(\mu+\frac{\mu_{t}}{\sigma_{\varepsilon}}\right) \frac{\partial \varepsilon}{\partial x_{j}}\right]+\rho C_{1} S_{\varepsilon}-\rho C_{2} \frac{\varepsilon^{2}}{k+\sqrt{v \varepsilon}}+ \\
C_{1 \varepsilon} \frac{\varepsilon}{k} C_{3 \varepsilon} G_{b}
\end{gathered}
$$

where $k$ is the turbulent kinetic energy $\left(\mathrm{m}^{2} / \mathrm{s}^{2}\right), \varepsilon$ is the turbulent dissipation rate $\left(\mathrm{m}^{2} / \mathrm{s}^{3}\right), \sigma_{k}$ and $\sigma_{\varepsilon}$ are the turbulent Prandtl numbers for $k$ and $\varepsilon$ respectively, $G_{k}$ and $G_{b}$ represents the generation of turbulent kinetic energy due to the mean velocity gradients and buoyancy respectively, $Y_{m}$ here is the contribution of the fluctuating dilation in compressible turbulence to the overall dissipation rate, $C_{s}$ are the constants and $S$ is the source term.

Discrete phase equations: In the Lagrangian formulation, the water droplet velocity is related to the rate of change of droplet position. The trajectory is predicted by using the force balance on the droplet which equates the particle inertia with the forces acting on the particle and it is written as:

$$
\frac{d u_{p}}{d t}=F_{D}\left(u-u_{p}\right)+\frac{g\left(\rho_{p}-\rho\right)}{\rho_{p}}+F_{x}
$$

where $u$ is the moist air velocity $(\mathrm{m} / \mathrm{s}), u_{p}$ is the droplet velocity $(\mathrm{m} / \mathrm{s}), F_{D}\left(u-u_{p}\right)$ is the drag force per unit droplet mass, $g$ is the gravitational acceleration $\left(\mathrm{m} / \mathrm{s}^{2}\right), \rho_{p}$ is the droplet density $\left(\mathrm{kg} / \mathrm{m}^{3}\right), \rho$ is the moist air density $\left(\mathrm{kg} / \mathrm{m}^{3}\right)$ and $F_{x}$ is the additional forces added as the source terms. The drag force is further expressed as:

$$
F_{D}=\frac{18 \mu}{\rho_{P} d_{p}^{2}} \frac{C_{D} R e}{24}
$$

Where $\mathrm{Cd}$ is the drag coefficient and is written in terms of the droplet's Reynolds and is expressed as:

$$
\begin{aligned}
& C_{D}=a_{1}+\frac{a_{2}}{R e}+\frac{a_{3}}{R e^{2}} \\
& R e=\frac{\rho d_{p}\left|u_{p}-u\right|}{\mu}
\end{aligned}
$$

where $d_{p}$ is the droplet diameter $(\mathrm{m}), C_{D}$ is the drag coefficient, $R e$ is the Reynolds number and $a_{1}, a_{2}$ and $a_{3}$ are constants.

The particle heat balance relates droplet temperature to the convective heat transfer is given as:

$$
m_{p} c_{p w} \frac{d T_{p}}{d t}=h A_{p}\left(T_{\infty}-T_{p}\right)
$$

where $m_{p}$ is the droplet mass $(\mathrm{kg}), c_{p w}$ is the water droplet heat capacity $(\mathrm{J} / \mathrm{kg} \cdot \mathrm{K}), A_{p}$ is the droplet surface area $\left(\mathrm{m}^{2}\right)$, $T_{\infty}$ is the local temperature of the continuous phase (K), $h$ is the convective heat transfer coefficient $\left(\mathrm{W} / \mathrm{m}^{2} \cdot \mathrm{K}\right)$ and $T_{p}$ is the droplet temperature $(\mathrm{K})$. The droplet temperature at the next time step is calculated by integrating the above equation and is expressed as:

$T_{p}(t+\Delta t)=T_{\infty}+\left(T_{p}(t)-T_{\infty}\right) e^{\left(-A_{p} h / m_{p} c_{p}\right) \Delta t}$ where $\Delta t$ is the integration time step. The heat transfer coefficient $(h)$ is calculated using the correlation as in Eq. 14.

$$
N u=\frac{h d_{p}}{k_{\infty}}=2.0+0.6 \operatorname{Re}_{d}^{1 / 2} \operatorname{Pr}^{1 / 3}
$$

where $N u$ is the Nusselt number, $k_{\infty}$ is the thermal conductivity of the continuous phase $(\mathrm{W} / \mathrm{m} \cdot \mathrm{K}), \operatorname{Re}_{d}$ is the Reynolds number based on the droplet diameter and the relative velocity and $\mathrm{Pr}$ is the Prandtl number of the continuous phase.

The rate of vaporization of water by air is related to the gradient of the vapor pressure between the droplet surface and the main air stream and is given as follows:

$$
\frac{d m_{p}}{d t}=A_{p} \frac{h_{m}}{R}\left(\frac{P_{s a t}\left(T_{p}\right)}{T_{p}}-C \frac{p}{T_{\infty}}\right)
$$

where $h_{m}$ is the mass transfer coefficient $(\mathrm{m} / \mathrm{s}), R$ is the universal gas constant $(\mathrm{J} / \mathrm{mol} \cdot \mathrm{K}), P_{\text {sat }}$ is the saturated vapor pressure and $C$ is the vapor concentration $\left(\mathrm{kmol} / \mathrm{m}^{3}\right)$. The mass transfer coefficient is calculated from Sherwood number $(S h)$ correlation as:

$$
S h=\frac{h_{m} d_{p}}{D_{v a}}=2.0+0.6 R e_{d}^{1 / 2} S c^{1 / 3}
$$

where $D_{v a}$ is the diffusion coefficient of vapor in the bulk $\left(\mathrm{m}^{2} / \mathrm{s}\right), \mathrm{Sc}$ is the Schmidt number. Therefore, the droplet mass is reduced according to the relation as:

$$
m_{p}(t+\Delta t)=m_{p}(t)-A_{p} \frac{h_{m}}{R}\left(\frac{P_{s a t}\left(T_{p}\right)}{T_{p}}-C \frac{p}{T_{\infty}}\right)(17)
$$


The droplet temperature is updated based on the heat balance relation between the sensible heat change in the droplet and the convective and evaporative heat transfer between the droplet and the air.

$$
m_{p} c_{p w} \frac{d T_{p}}{d t}=h A_{p}\left(T_{\infty}-T_{p}\right)+\frac{d m_{p}}{d t} h_{f g}
$$

where $h_{f g}$ is the latent heat of vaporization $(\mathrm{J} / \mathrm{kg})$.

\subsection{Coupling Between Air and Water Phases}

The heat, mass and momentum of the droplet during its trajectory is evaluated and are incorporated as source/sink terms in the respective continuous phase equations. These three equations for the momentum, the mass and the heat exchanges are expressed as:

$$
\begin{gathered}
F=\sum\left(\frac{18 \mu}{\rho_{P} d_{p}^{2}} \frac{C_{D} R e}{24}\left(u-u_{p}\right)+F_{\text {other }}\right) \frac{d m_{p}}{d t} \Delta t \\
M=\frac{\Delta m_{p}}{m_{p, 0}} \dot{m}_{p, 0} \\
Q=\left[\frac{m_{p, a v}}{m_{p, 0}} c_{p w} \Delta T_{p}+\frac{\Delta m_{p}}{m_{p, 0}}\left(-h_{f g}+\int_{T_{r e f}}^{T_{p}} c_{p v} d T\right)\right] \dot{m}_{p, 0}
\end{gathered}
$$

where $F_{\text {other }}$ are other interaction forces, $c_{p w}$ is the heat capacity of the water droplet $(\mathrm{J} / \mathrm{kg} \cdot \mathrm{K}), c_{p v}$ is the heat capacity of the water vapor $(\mathrm{J} / \mathrm{kg} \cdot \mathrm{K}), \dot{m}_{p, 0}$ is the initial mass flow rate of the droplet injection $(\mathrm{kg} / \mathrm{s}), m_{p, 0}$ is the initial mass of the droplet $(\mathrm{kg}), m_{p, a v}$ is the average mass of the droplet in the cell $(\mathrm{kg}), T_{\text {ref }}$ is the reference temperature $(\mathrm{K}), \Delta T_{p}$ is the change in temperature $(\mathrm{K})$ and $\Delta m_{p}$ is the change in mass of the droplet $(\mathrm{kg})$.

\subsection{Boundary Conditions}

As the flow operating velocity and the expected flow field is relatively low $(0-10 \mathrm{~m} / \mathrm{s})$ the flow is considered incompressible. It is driven by the assigned velocity, relative humidity or moisture fraction, and temperature values (Dirichlet) at the very top entry of the wind catcher. The two outlets/windows of the computational domain are specified as outflow at an equal proportion for the flow of $50 \%$ to insure proper conditioning and the solution near these windows are not affected by the back/reverse flow conditions. Practically, this can be achieved by means of a simple suction fan. The geometry walls are all subjected to zero velocity and thermally either insulated wall (i.e. ground), or coupled wall (i.e. ceiling), or convective wall (i.e. the surroundings geometry). The mist is introduced via line injections which are defined (injection angle, velocity, mist size) and uniformly distributed at the very top near the entry of the wind catcher (see Fig. 1). Droplet evaporation has been considered with uniform droplet diameter distribution. The droplet diameter is preset at $10 \mu \mathrm{m}$ with a cone angle of $60^{\circ}$. The water is sprayed at a rate of 0.1 $\mathrm{kg} / \mathrm{s}$ with a velocity of $2 \mathrm{~m} / \mathrm{s}$ and temperature $300 \mathrm{~K}$. The water droplets have been assumed to have inelastic collisions with the walls of the wind catcher. Hence, the reflected water droplet will have only tangential component of the momentum.

\subsection{Computational Domain and Mesh Sensitivity}

The grid consists of a quadrilateral structured surface mesh type. The baseline mesh is shown in Fig. 1 with a total cells of 48,896, 99,012 faces and 50,115 nodes. The maximum and minimum cells areas are $0.0002 \mathrm{~m}^{2}$ and $0.0164 \mathrm{~m}^{2}$, respectively. The discretization and its clustering in the grid was normally kept to the wall and smoothly extended in the anticipated high gradient velocity and pressures to ensure good accuracy in the results. Furthermore, The baseline grid is modified and three other levels were generated and denoted as Coarse, Coarse-I, and Fine by respectively halving the number of grids in both directions, halving in the axial direction, and doubling in both directions from the baseline mesh clustering/inflation.

The solution was carried using the commercial CFD code FLUENT based on finite volume approach. Segregated solver which provides good robustness has been used. Reynold-averaged Navier-stokes (RANS) equations with the constitutive eddy viscosity realizable $k-\varepsilon$ turbulence model are solved with Boussinesq hypothesis and discrete phase injections. The semi-implicit method for pressurelinked equations (SIMPLE) algorithm is chosen for pressure-velocity coupling and second order upwind discretization scheme is employed for spatial derivatives properties. The convergence criterion is set at $1 \times 10^{-5}$ residual for the continuity, and three momentums and energy scalar equations. Sensitivity analysis is carried out to verify the solution mesh independency using the same boundary conditions. The weighted mass average values at the bottom and top outlets are used to illustrate the discrepancy (see Table 1). As the temperature and relative humidity were more consistent with less than $1 \%$ error across all mesh levels, the velocity values were used as the error indicator. As seen in table 1 , the maximum obtained error between the fine and baseline was $2.3 \%$ $( \pm 0.0544 \mathrm{~m} / \mathrm{s})$ in the bottom room exit and $4.4 \%$ $( \pm 0.1027 \mathrm{~m} / \mathrm{s})$ in the top room exit. The error however was more exaggerated for the coarse and half coarse mesh levels reaching as high as $9.8 \%$ and $5.7 \%$ in the bottom room and $55 \%$ and $27.9 \%$ in the top room, respectively. Therefore, the baseline mesh can be confidently used to

\begin{tabular}{|c|c|c|c|c|c|c|c|c|}
\hline \multirow{2}{*}{$\begin{array}{l}\text { Region } \\
\begin{array}{l}\text { Bottom } \\
\text { outlet }\end{array}\end{array}$} & \multicolumn{2}{|c|}{$\begin{array}{l}\text { Coarse Vel. } \\
(\mathrm{m} / \mathrm{s}) \text { \&Err. }\end{array}$} & \multicolumn{2}{|c|}{$\begin{array}{l}\text { Coarse-I Vel. } \\
(\mathrm{m} / \mathrm{s}) \& \text { Err. }\end{array}$} & \multicolumn{2}{|c|}{$\begin{array}{l}\text { Baseline Vel. } \\
\text { (m/s) \&Err. }\end{array}$} & \multicolumn{2}{|c|}{$\begin{array}{l}\text { Fine Vel. } \\
(\mathrm{m} / \mathrm{s})\end{array}$} \\
\hline & & & & $.7 \%$ & & $2.3 \%$ & 2.3275 & \\
\hline $\begin{array}{l}\text { Top } \\
\text { Outlet }\end{array}$ & 3.5749 & $55.3 \%$ & 2.9456 & $27.9 \%$ & 2.4051 & $4.4 \%$ & 2.3024 & \\
\hline
\end{tabular}
carry further analysis without sizeable influence on the subsequent results.

Table 1: Summary of mesh sensitivity study

\section{Results and Discussion}

\subsection{Baseline at $42^{\circ} \mathrm{C}$ and $50 \%$ Relative Humidity}




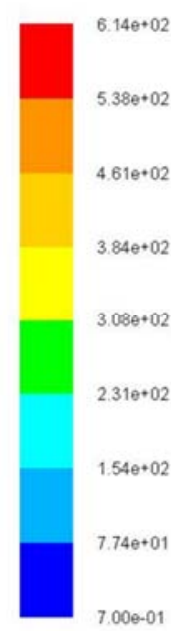

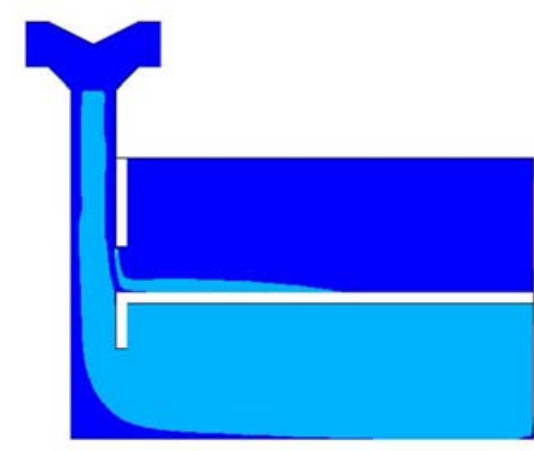

RH\%
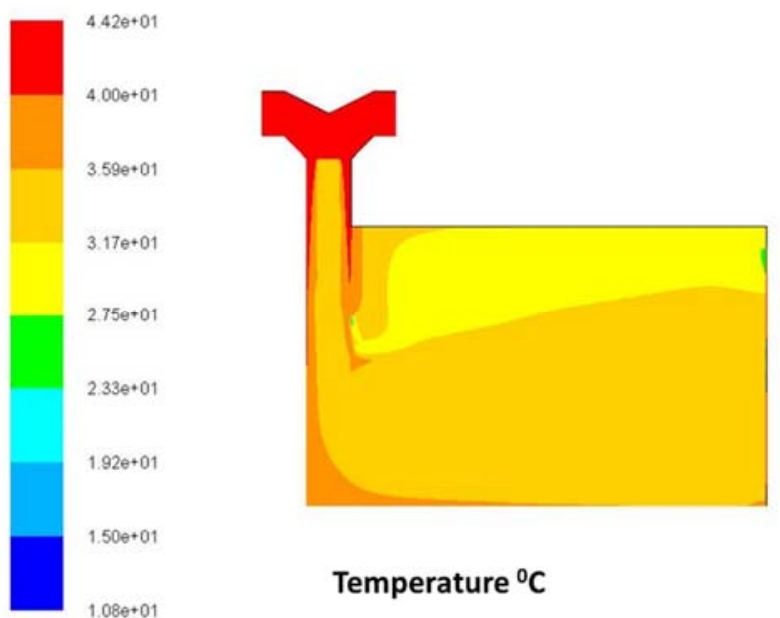

Temperature ${ }^{\circ} \mathrm{C}$

Fig. 2: Relative humidity and temperature contours for the initial baseline case

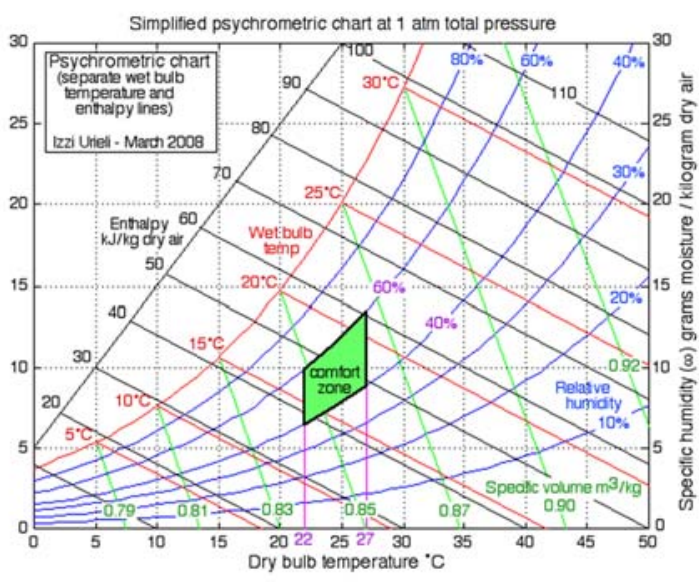

Fig. 3: Targeted comfort zone

As per the climate of the UAE, the initial baseline inlet temperature and relative humidity for summer conditions were identified to be $42^{\circ} \mathrm{C}$ and $50 \%$ [9]. Using the psychrometric chart the humidity ratio (w) was calculated for these conditions. The inlet humidity is prescribed to the model in the form of mass fraction of water vapor $\left(\mathrm{m}_{\mathrm{fw}}\right)$. The mass fraction of water vapor was calculated from the humidity ratio according to Eq. 22. For 50\% relative humidity this $\mathrm{m}_{\mathrm{fw}}$ was calculated to be 0.026 .

$$
m_{f w}=\frac{w}{1+w}
$$

The simulation was carried out for a nominal wind velocity of approximately $4 \mathrm{~m} / \mathrm{s}$ and the lowest tower height of $7.75 \mathrm{~m}$. The contours of temperature and relative humidity are shown in Fig. 2. The results show that at these conditions and even at a low mass flow rate from the injectors $(0.01 \mathrm{~kg} / \mathrm{s})$ the inside of the rooms was far from the comfort zone due to the incoming high relative humidity. The maximum relative humidity in the rooms (at outlet) reached up to $80.41 \%$. The temperature also remained high at $35^{\circ} \mathrm{C}$. To bring down the temperature one may need to deploy a higher mass flow rate through the injectors; unfortunately this will lead to humidity levels above $80 \%$ and further depart from the human comfort zone (see Fig. 3). This implies that inlet air relative humidity has to be reduced/dehumidified before even reaching the injectors. This calls for primary dehumidification of the inlet air. To avoid using energy in this dehumidification process special hydrophilic and water absorbent/hydrophilic materials such as silica gels or zirconia based material can be used. However this is another research area which is beyond the scope of this paper. Hereon the simulation were carried out with an assumption of dehumidified air with relative humidity brought down to $25 \%$ and at the constant temperature of $42^{0} \mathrm{C}$.

\subsection{Sensitivity to height}

The height of the wind catcher could play some role in optimizing the functionality. Two heights were considered for this study. The lowest height of the wind catcher had a 7.75 meter tall tower. Whereas the tallest wind catcher had a tower height of 12.25 meter (see Fig. 1). Thee analysis was carried out at $42{ }^{\circ} \mathrm{C}$ inlet temperature, $25 \%$ relative humidity, and injector mass flow rate of $0.01 \mathrm{~kg} / \mathrm{s}$. The results are shown in Fig. 4. Results show that increase in height does slightly reduce the temperature and increases the humidity in the rooms. To study the difference created by varying the height, the mass weighted average of temperature and relative humidity at both rooms (at outlets) were evaluated. For the case with small height the average temperature and relative humidity recorded in the top room were $37.24{ }^{\circ} \mathrm{C}$ and $38.3 \%$ and that in the bottom room were $37.3{ }^{\circ} \mathrm{C}$ and $38.4 \%$, respectively. However with a taller tower, the average temperature and relative humidity in the top room were $36.92{ }^{\circ} \mathrm{C}$ and $39.13 \%$ and in the bottom room they were $36.96{ }^{\circ} \mathrm{C}$ and $39.06 \%$. The temperature in both the rooms remained almost the same but the relative humidity was considerably higher, especially in the top room. This 


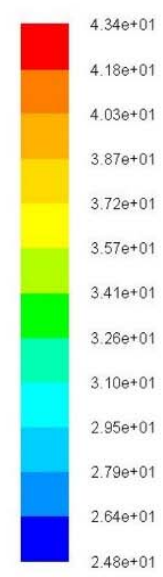

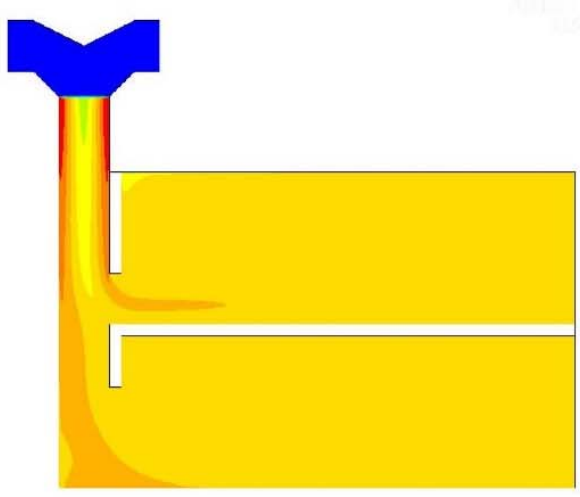

RH\%

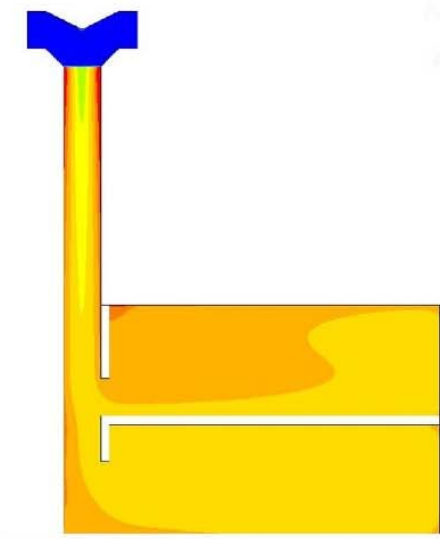

RH\%
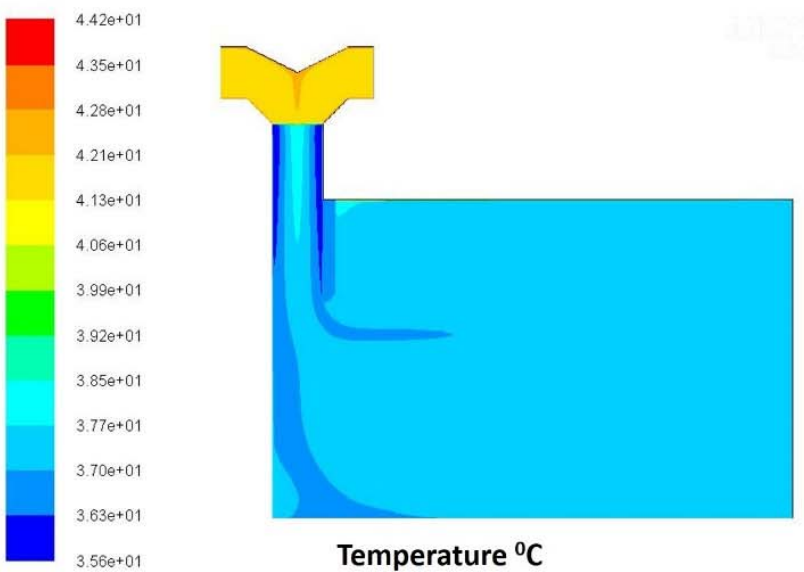

Temperature ${ }^{\circ} \mathrm{C}$

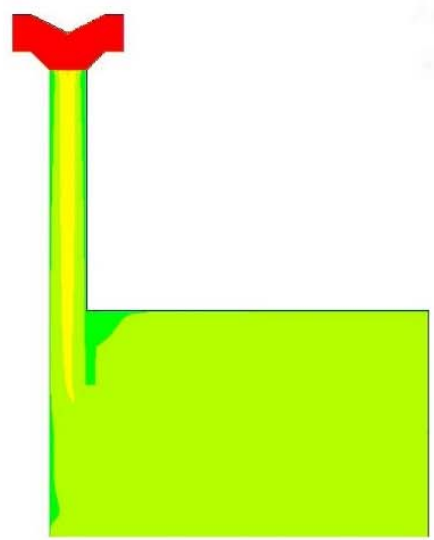

Temperature ${ }^{\circ} \mathrm{C}$

Fig. 4: RH and Temperature contours for cases of different heights

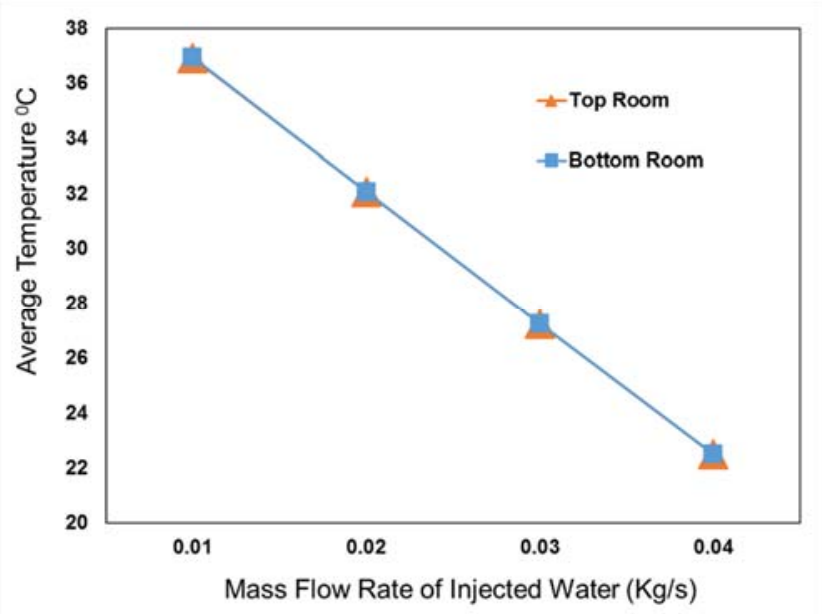

Fig. 5: Variation in temperature in the top and bottom rooms for varying mass flow rate of injected water

effect is attributed to the fact that a taller tower enhances the residence/traveling time of the air coming through the inlets. Theoretically, higher residence time allows the water from the injectors to completely vaporize and the flow to become more homogenized before entering the rooms. Duct vaporization of the injected water also implies better mixing of the air and vapor which leads to a higher relative humidity. A secondary effect is the

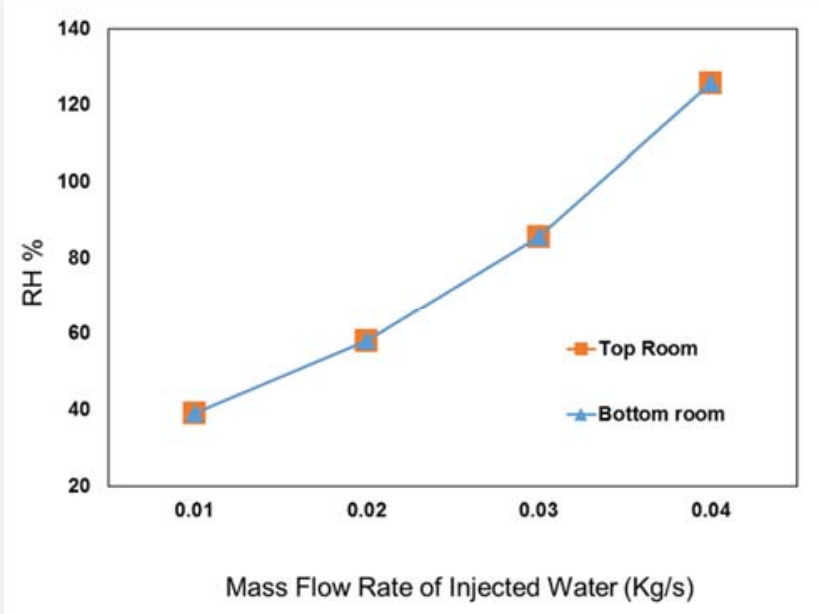

Fig. 6: Variation in RH in the top and bottom rooms for varying mass flow rate of injected water

property of the flow being homogenous or heterogeneous which will affect the flow accordingly. It should be noted that previous work of Badran [4] and lower fidelity work [6] [7] used are insensitive to account for the temperature and relative humidity distribution. To have the best use of the injectors we need to allow the water to sufficiently vaporize and contribute to both the cooling of air and the increase of the relative humidity and this could be 
achieved by having a taller tower. Therefore a taller tower is considered in rest of the studies.

\subsection{Sensitivity to the injector mass flow rate}

The injectors are the most important components for the effectiveness of a wind catcher. This is the only control mechanism for the temperature and humidity of the air entering the rooms assuming that it is sufficiently predehumidified. This is the main heat sink in the whole thermodynamic system involving the tower and the rooms. Therefore, it is crucial to have the best setup for the injectors. The major parameter that governs the role of the injector is the flow rate for water being injected. The nominal mist size, size distribution, and their trajectory play a secondary effect. Thermodynamically,

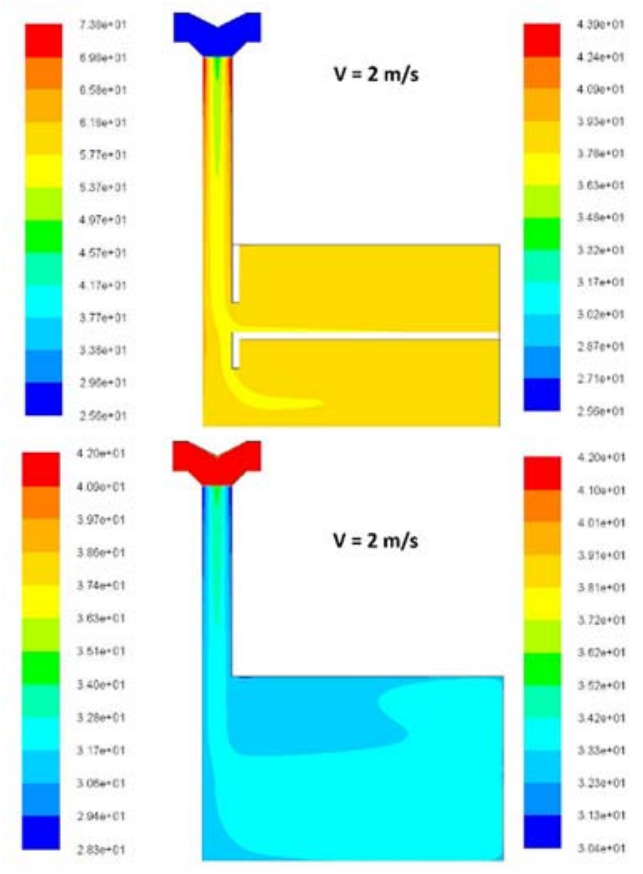

the heat that could be possibly absorbed from the inlet air can be calculated by the product of this flow rate and the latent heat of vaporization of water. Therefore to optimize the use of the injectors it is necessary to study the effect of the flow rate.

In this sensitivity analysis, four flow rates were considered. Starting with $0.01 \mathrm{Kg} / \mathrm{s}$, the flow rate was stepped by $0.01 \mathrm{Kg} / \mathrm{s}$ increment up to $0.04 \mathrm{Kg} / \mathrm{s}$. The height of tower was 12.25 meters and wind speed was 4 $\mathrm{m} / \mathrm{s}$. Fig. 5 shows the variation of average temperature and Fig. 6 shows the variation of relative humidity in top and bottom rooms. It was noticed from the results that at the least mass flow rate of injected water $(0.01 \mathrm{Kg} / \mathrm{s})$ there was a temperature drop of approximately $6{ }^{\circ} \mathrm{C}$ from the ambient and a relative humidity increase of $15 \%$. The maximum temperature drop was $20^{\circ} \mathrm{C}$ for the maximum

Fig. 7: RH (top) and Temperature (bottom) contours for cases of different inlet velocities

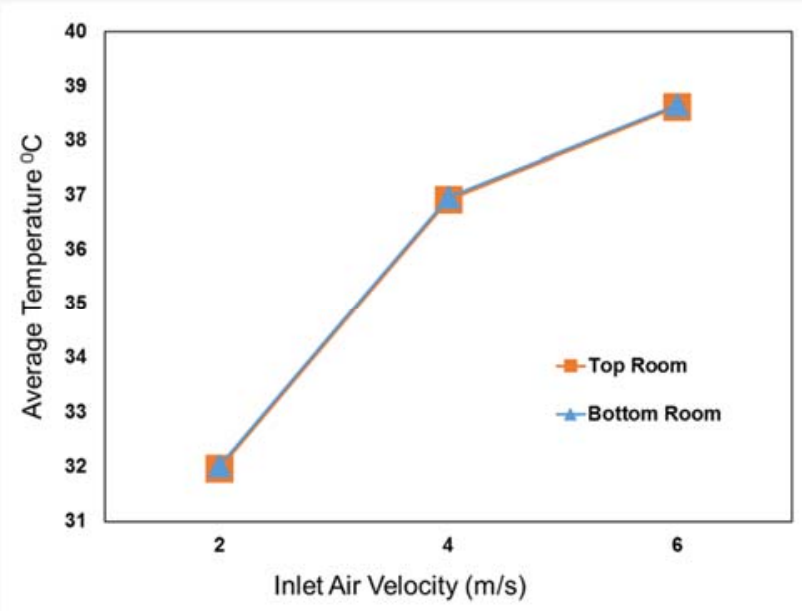

Fig. 8: Variation in temperature in the top and bottom rooms for varying air velocity

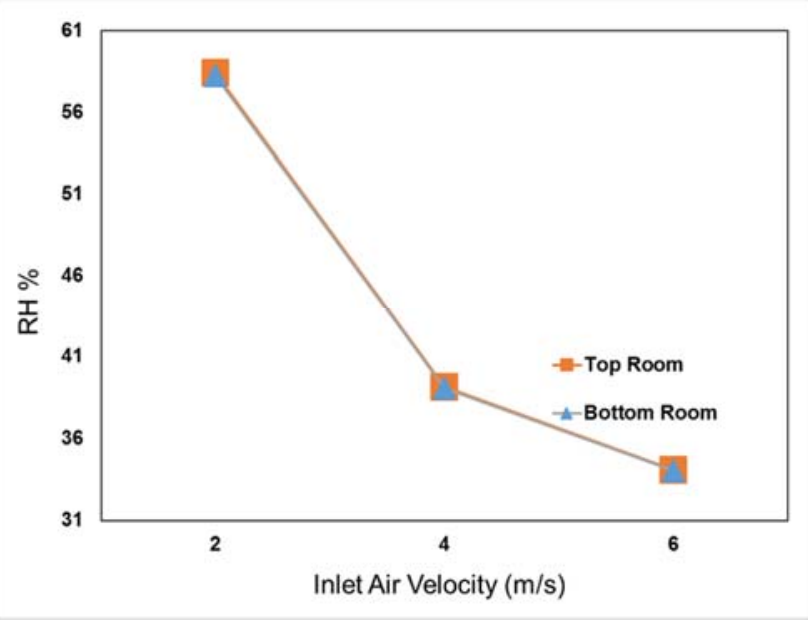

Fig. 9: Variation in RH in the top and bottom rooms for varying air velocity 
flow rate of $0.04 \mathrm{Kg} / \mathrm{s}$ but the relative humidity in this case exceeded $100 \%$ implying that the water injected did not have sufficient residence time to vaporize and hence exists in a condensed form. Cross examine these values on the psychrometric charts indeed shows the air is becoming oversaturated which leads to condensation. The oversaturation is computationally indicated by beyond the practically $100 \%$ relative humidity value. In all cases the temperature and relative humidity in both the rooms remained closely identical. The result as seen here is highly undesirable, hence a high flow rate from the injectors must be avoided.

At intermediate flow rates of $0.02 \mathrm{~kg} / \mathrm{s}$ and $0.03 \mathrm{~kg} / \mathrm{s}$ the temperature drop was $10^{\circ} \mathrm{C}$ and $15^{\circ} \mathrm{C}$ and the average temperature in the rooms was $32.08{ }^{\circ} \mathrm{C}$ and $27.26{ }^{\circ} \mathrm{C}$, respectively. The relative humidity closest to the comfort levels was for flow rate of $0.02 \mathrm{Kg} / \mathrm{s}$ and was found to be $58.1 \%$. At $0.03 \mathrm{Kg} / \mathrm{s}$ mass flow rate the relative humidity increased to $85.7 \%$. Therefore with respect to this sensitivity case the flow rate of $0.02 \mathrm{Kg} / \mathrm{s}$ seemed to give the best results as the temperature and the relative humidity were relatively close to the comfort levels. However it must be pointed out here that the flow rate case of $0.03 \mathrm{Kg} / \mathrm{s}$ provided the best temperature condition but with a very high relative humidity. This flow rate could be pursued if there is extra dehumidification of the inlet air.

\subsection{Sensitivity to the inlet velocity}

The inlet velocity for the wind tower is geography dependent which makes it uncontrollable unless there is addition of diffuser or nozzle shaped inlets to the wind catcher that promote harnessing more wind. Through these additions the velocity can be modified to suit the needs. Here, in this study we directly model the implications of such additions by varying the inlet velocity of air. This study also corresponds to the unprecedented changes in wind speeds occurring due to weather conditions. Three wind speeds were considered 2,4 and $6 \mathrm{~m} / \mathrm{s}$ and these are characteristic to the UAE region. The flow rate if the injectors was fixed at 0.01 $\mathrm{Kg} / \mathrm{s}$ and the tower height was 12.25 meter. The contours for temperature and relative humidity are shown in Fig. 7 whereas Fig. 8 and 9 show the variation of temperature and relative humidity in different rooms for different cases.

As expected, it was observed that with increase in velocity there was an increase in room temperature and a decrease in relative humidity. Similar to the mass flow rate sensitivity study the temperature and relative humidity in both the rooms remained closely identical. The maximum room temperature was $38.65{ }^{\circ} \mathrm{C}$ and relative humidity $34.03 \%$ (bottom room) for velocity at $6 \mathrm{~m} / \mathrm{s}$ and the minimum was $31.97^{\circ} \mathrm{C}$ and relative humidity $58.41 \%$ (top room) at velocity of $2 \mathrm{~m} / \mathrm{s}$. A higher velocity implies higher influx of water in the form of relative humidity, but at the same time, it also implies higher influx of high temperature air that occupies a larger mass fraction. When the mass flow rate of injected water is constant then higher velocity results in the increase of temperature which exactly what the results are showing. Therefore, lower velocities are better for the effectiveness of the wind catcher or alternatively one needs to adjust/increase the water injection with the increase of incoming velocity to take advantage of higher incoming velocity. Table 2 lists the summary of the temperature and relative humidity for all the considered cases in this work.

Table 2: Temperature and relative humidity data for different cases in different rooms

\begin{tabular}{|c|c|c|c|c|}
\hline \multirow[b]{2}{*}{ Case } & \multicolumn{2}{|c|}{ Top Room } & \multicolumn{2}{|c|}{ Bottom Room } \\
\hline & $\begin{array}{l}\text { Temperature } \\
{ }^{\circ} \mathrm{C}\end{array}$ & $\begin{array}{c}\text { Relative } \\
\text { Humidity \% }\end{array}$ & Temperature ${ }^{\circ} \mathrm{C}$ & $\begin{array}{c}\text { Relative } \\
\text { Humidity } \\
\%\end{array}$ \\
\hline $\begin{array}{l}\text { Temp }=42 \mathrm{C}, \mathrm{RH}=50 \% \text {, Vel. }=4 \mathrm{~m} / \mathrm{s} \\
\text { mass flow rate }=0.01 \mathrm{Kg} / \mathrm{s}, \mathrm{H}=7.75 \mathrm{~m} .\end{array}$ & 31.35 & 56.83 & 35.35 & 80.41 \\
\hline $\begin{array}{l}\text { Temp }=42 \mathrm{C}, \mathrm{RH}=25 \% \text {, Vel. }=4 \mathrm{~m} / \mathrm{s} \\
\text { mass flow rate }=0.01 \mathrm{Kg} / \mathrm{s}, \mathrm{H}=7.75 \mathrm{~m} .\end{array}$ & 37.2 & 38.32 & 37.28 & 38.37 \\
\hline $\begin{array}{c}\text { Temp }=42 \mathrm{C}, \mathrm{RH}=25 \% \text {, Vel. }=4 \mathrm{~m} / \mathrm{s} \\
\text { mass flow rate }=0.01 \mathrm{Kg} / \mathrm{s}, \mathrm{H}=12.25 \mathrm{~m} .\end{array}$ & 36.92 & 39.13 & 36.96 & 39.06 \\
\hline $\begin{array}{c}\text { Temp }=42 \mathrm{C}, \mathrm{RH}=25 \% \text {, Vel. }=4 \mathrm{~m} / \mathrm{s} \\
\text { mass flow rate }=0.02 \mathrm{Kg} / \mathrm{s}, \mathrm{H}=12.25 \mathrm{~m} .\end{array}$ & 32.07 & 58.1 & 32.09 & 58.03 \\
\hline $\begin{array}{l}\text { Temp }=42 \mathrm{C}, \mathrm{RH}=25 \% \text {, Vel. }=4 \mathrm{~m} / \mathrm{s} \\
\text { mass flow rate }=0.03 \mathrm{Kg} / \mathrm{s}, \mathrm{H}=12.25 \mathrm{~m} .\end{array}$ & 27.26 & 85.65 & 27.26 & 85.67 \\
\hline $\begin{array}{c}\text { Temp }=42 \mathrm{C}, \mathrm{RH}=25 \% \text {, Vel. }=4 \mathrm{~m} / \mathrm{s} \\
\text { mass flow rate }=0.04 \mathrm{Kg} / \mathrm{s}, \mathrm{H}=12.25 \mathrm{~m} .\end{array}$ & 22.52 & 125.73 & 22.52 & 125.72 \\
\hline $\begin{array}{c}\text { Temp }=42 \mathrm{C}, \mathrm{RH}=25 \% \text {, Vel. }=2 \mathrm{~m} / \mathrm{s} \\
\text { mass flow rate }=0.01 \mathrm{Kg} / \mathrm{s}, \mathrm{H}=12.25 \mathrm{~m} .\end{array}$ & 31.97 & 58.41 & 32.02 & 58.26 \\
\hline $\begin{array}{l}\text { Temp }=42 \mathrm{C}, \mathrm{RH}=25 \% \text {, Vel. }=6 \mathrm{~m} / \mathrm{s} \\
\text { mass flow rate }=0.01 \mathrm{Kg} / \mathrm{s}, \mathrm{H}=12.25 \mathrm{~m} .\end{array}$ & 38.61 & 34.09 & 38.65 & 34.03 \\
\hline
\end{tabular}




\section{Conclusion}

The potential of wind catcher in providing occupants comfort conditions is been numerically investigated here. A non-isothermal coupled steady Navies-stokes flow of two species used to evaluate the human comfort in a simple two-level dwelling.

Using the arid climate conditions of the UAE in particular, the flow parameters including velocity, temperature, relative humidity and droplets dispersion are evaluated and their distribution were presented. Initially at nominal temperature and relative humidity of $42{ }^{\circ} \mathrm{C}$ and $50 \%$ respectively, the role of wind catcher in evaporative cooling was deemed unimportant. Suggesting a constant temperature pre-dehumidification is necessary and taking advantages of recent developed in hydrophilic materials. As the entering relative humidity level is adjusted/reduced at presumed value near $25 \%$, the potential of evaporative cooling is exasperated. At these conditions $\left(42^{\circ} \mathrm{C}\right.$ and $25 \%$ relative humidity) a significant temperature drop of $10^{\circ} \mathrm{C}$ and practical relative humidity of $58 \%$ was obtained. The influence of the wind catcher's height in providing sufficient time for mist evaporation and homogenizing the flow as well as the undesirable role of the higher velocity under fixed mist mas flow was highlighted.

\section{Acknowledgment}

The students of the fall 2015 computational fluid dynamics course (MEG603) in particular Mohammed Khan and Kamal Adouane at Masdar institute are highly acknowledged for their collection of this topic.

\section{References}

[1] N.S. Billington, B.M. Roberts, Building Services Engineering: A Review of its Development, vol. 1, International Series on Building Environmental Engineering, Pergamon Press, Oxford, 1982.

[2] M.N. Bahadori, An improved design of wind towers for natural Ventilation and passive cooling, Solar Energy 35 (2) (1985) 119-129.

[3] K. Kent, T.L. Thompson, Natural draft evaporative cooling, in: Proceedings of the ASES Annual Conference and the 15th National Passive Solar Conference, Austin, TX, 1990.

[4] A.A. Badran, Performance of cool towers under various climates in Jordan, Energy and Buildings 35 (2003) 1031-1035.

[5] M.H. Ghadiri, M.F. Mohamed, N.L.N. Ibrahim, CFD analysis of natural ventilation behavior in four sided wind catcher, International Journal of Mechanical, Aerospace, Industrial, Mechatronic and Manufacturing Engineering, 6(12), 2012.

[6] Y. Su, S.B. Riffat, Y.L. Lin, N. Khan, Experimental and CFD study of ventilation flow rate of a Monodraught ${ }^{\mathrm{TM}}$ wind catcher, Energy and Buildings 40, 1110-1116, 2008.

[7] H. Montazeri, F. Montazeri, R. Azizian, S. Mostafavi, Two-sided Wind Catcher Performance Evaluation Using Experimental, Numerical and Analytical Modeling, Renewable Energy, 35, 1424-1435, 2010.

[8] I. Janajreh, D. Suwwan, R. Hashaikeh, Assessment of direct contact membrane distillation under different configurations, velocities and membrane properties, Applied doi.org/10.1016/j.apenergy.2016.05.020, 2016.

[9] Country Overview for United Arab Emirates. www.myweather2.com. 